\title{
Estimate of undergraduate university student alcohol use in China: a systematic review and meta-analysis
}

\author{
lan Newman* ${ }^{*}$, Lanyan Ding and Yonghua Feng
}

\begin{abstract}
Objective: To develop an estimate of self-reported last 30 day alcohol use by university students in China.

Methods: A search of papers published in English and Chinese between 2006 and 2015, following pre-established selection criteria, identified 30 papers that were included in this meta-analysis. Nine moderator variables were preselected for this analysis.

Results: A total of 749 papers were identified in the keyword search, and 30 studies (28 in Chinese, 2 in English) met all selection criteria and were included in the meta-analysis. The self-reported last-30-day alcohol use for undergraduate university students was $66.8 \%$ for males and $31.7 \%$ for females. Meta-regression identified three moderators associated with the different drinking rates reported: the definition of drinking, the origin of the questionnaire used in the survey, and the geographic region where the survey was conducted. These three moderators explained $56 \%$ of the heterogeneity of reported drinking rates for the male students and $47 \%$ of the heterogeneity of reported drinking rates for the female students.

Conclusions: The results of this meta-analysis provide an estimate of last 30 day alcohol use by university students (age 18-23) and increase our understanding of drinking by young people in China. The meta-analysis suggested three variables that could have affected the results and which are worthy of further study. The discussion places these results in the context of Chinese drinking culture and university life.
\end{abstract}

Keywords: Alcohol, China, Drinking, University students, Meta-analysis

\section{Introduction}

The World Health Organization (WHO) suggests a 36\% increase in per capita alcohol consumption in liters of pure alcohol in China between 2003-2005 and 20082010 [1]. In 2014, WHO estimated that $58.4 \%$ of adult males and $28.9 \%$ of adult females in China had consumed alcohol in 2010 [2]. While these data and others from large national surveys among different populations [3-8] provide the best estimates of drinking patterns, there are few studies that describe drinking among the younger population. Data from the younger population has the potential to suggest something about trajectory towards these adult drinking patterns [9]. For example, a recent

\footnotetext{
*Correspondence: inewman1@unl.edu

Nebraska Prevention Center for Alcohol and Drug Abuse, Department of Educational Psychology, University of Nebraska-Lincoln, PO Box 880345, Lincoln, NE 68588-0345, USA
}

meta-analysis of studies published between 2007 and 2015 of drinking rates of Chinese adolescents in middle school (ages 13-15) and high-school (ages 16-18) suggests that $36.5 \%$ of the males and $21.2 \%$ of the females in high school had consumed alcohol in the previous 30 days as had $23.6 \%$ of the males and $15.3 \%$ of the females in middle schools. The highest drinking rates-44.7\% of the males and $28.8 \%$ of the females - were among vocational high school students (students not intending to take the national college entry exam or study at university) [10].

To further explore the trajectory of adolescent to adult drinking, this project was developed to analyze last 30 day alcohol use among Chinese undergraduate university students that were reported in papers published between 2006 and 2015 in English and Chinese.

Students who enter university in China follow a specific educational path. The nation provides compulsory 
general education through middle school (age 15). At the completion of middle school, university-bound students enter a regular high school, and the other students enter a vocational high school. Vocational high schools prepare students with the technical skills to directly enter the workforce after 2 to 3 years. The regular high school students, meanwhile, attend high school for three years and take the national university entrance exam (gaokao) at the end of their 3rd year. This is a highly competitive educational path, and the gaokao result determines which universities will accept a student's application for admission. The higher the student's score on the gaokao, the greater his/her chance of being admitted to one of the more prestigious universities. Students with lower scores will apply to less prestigious universities or to community colleges/city colleges. The community/city college option results in a three-year degree, the university option results in a four-year degree.

Entering university represents a significant lifestyle change for most students. The new environment places new demands for self-regulation in the absence of family regulation. Western research literature describes the beginning of university as a time of experimentation often associated with increased alcohol use [11]. Our research group is interested in understanding alcohol use in different life stages-from adolescence to adulthood. This meta-analysis focused on studies of alcohol use by Chinese undergraduate university students, who typically are 18-23 years old. This paper complements an earlier meta-analysis of studies of alcohol use among Chinese middle and high school students [10].

Two research questions guided this study:

1. What is the 30-day drinking rate for male Chinese undergraduate university students?

2. What is the 30-day drinking rate for female Chinese undergraduate university students?

\section{Method}

\section{Research protocol}

The Preferred Reporting Items for Systematic Reviews and Meta-Analysis (PRISMA) guided this project (http://www.prisma-statement.org/PRISMAStatement/ PRISMAStatement.aspx).

\section{Information sources search strategy}

We conducted an online search of four databases: China National Knowledge Infrastructure database (CNKI) [12], Wanfang (WF) [13], PubMed (PM) [14], and Web of Science (WS) [15]. In each database we searched for papers published between 2006 and 2015. Initially we searched for titles and abstracts containing the keywords: college students/university students AND alcohol use/drinking AND China/Chinese.

\section{Eligibility Criteria}

Five pre-established criteria were determined for a study's inclusion in the analysis. Papers had to 1) be based on original data, 2) report the last 30-day drinking rate, 3) report drinking rates by gender, 4) describe students attending a university/college in Mainland China, 5) be published in a peer-reviewed journal in English or Chinese between 2006 and 2015.

\section{Original data}

To increase the integrity of the data used in the metaanalysis we selected only papers reporting on original survey data. Articles using duplicated data or secondary sources were excluded.

\section{Last 30-day drinking rate}

Previous studies have estimated drinking rate in the past seven days, 30 days, three months, six months and last year. We selected the past 30 day recall because it was the most frequently used, because it allowed sufficient time to capture drinking behaviors, and because it was less subject to memory error than longer recall periods [16]. Alcohol quantity data were not used in this meta-analysis. Selfreported estimates of alcohol quantity in China are confounded by a number of factors such as the absence of a standardized drink size, wide variation in the strength of beverage alcohols, access to unlabeled home-made and unrecorded alcohols, drinking from different sizes of cups and bowls, and a variety of drinking customs [17-19].

\section{Gender}

Previous surveys of drinking behavior in China have suggested there are significant differences in the drinking rates of males and females $[1,3,18,20]$. These gender differences reflect social attitudes about gender roles and drinking [21]. Both national and regional studies of alcohol consumption among Chinese university students have indicated gender differences $[8,9]$.

\section{Mainland China}

Hong Kong, Macau and Taiwan were excluded because their recent history differs significantly from that of the Mainland. Studies of Chinese students in other countries were excluded.

\section{Published in English or Chinese}

We recognize there may be relevant studies published in other languages, but we lacked the resources to seek them out.

\section{Methodology quality assessment}

The search of the two Chinese databases and two American databases was done twice by one reviewer to ensure we captured all of the possible studies relating to 
our research questions. Eligibility for inclusion was assessed by two reviewers independently. Any disagreements between the two reviewers were discussed until consensus was reached. If there was no consensus, the paper was excluded. To ensure the methodological quality of the papers included in this meta-analysis, the guidance tool Quality Assessment of Systematic Reviews and Meta-Analyses (NIH) was used [22]. Two reviewers independently rated the quality on each of eight items listed in this quality assessment scale from good, fair, to poor. Data extractions was carried out by two researchers independently and the results were compared. Publication bias and heterogeneity were assessed in a meta-analysis.

\section{Outcome variables and moderator variables}

The outcome variable for this study was the logit of the self-reported drinking rates of male and female undergraduate students in China.

The importance of moderator variables in metaanalyses has been noted by Groves and Lyberg [23], Moher et al. [24] and Feng and Newman [10]. Based on their recommendations and the comments from Chinese and American researchers who had considerable experience studying alcohol use in China, nine moderator variables were identified. They were: 1) year the study was conducted, 2) the number of universities surveyed, 3) the response rate, 4) the origin of the alcohol use questionnaire, 5) a clearly stated definition of drinking as having at least one cup of alcohol beverage, 6) trained or untrained data collectors, 7) four-year or three-year university degree program, 8) the geographic region of the study, and 9) the sample size.

The moderator variable for origin of the alcohol use questionnaire was identified for the following reason: Often, in emerging areas of investigation, the survey questions are developed by individual investigators. One earlier attempt to summarize findings from studies done between 1994 and 2004 of university student drinking in China failed partly because of the great diversity of investigator-developed alcohol use questions [9]. In contrast to that earlier attempt, this study found that 20 of the 30 papers identified contained alcohol use questions based on the Youth Risk Behavior Survey (YRBS). The YRBS was developed by the US Centers for Disease Control and Prevention and first administered in the USA in 1991. The YRBS aimed to standardize data collection about epidemiologically identified health risk factors of adolescents. The questions have been refined through frequent use and revision; consequently the questions tend to be more specific. The YRBS questionnaire continues to be used in the United States and has influenced adolescent health surveys worldwide with its standardized questions of clearly-defined behaviors. The contribution of the YRBS to the improvement of survey instruments is evidenced in this collection of papers. Judging by this sample of alcohol use studies in China, it appears that beginning in 2006 standardized alcohol use questionnaires based on the YRBS began replacing investigator-developed alcohol use questionnaires.

\section{Moderator coding}

The year the study was conducted, the number of schools surveyed, and the response rate were treated as continuous variables. The origin of alcohol use questionnaire was dummy coded as Youth Risk Behavior Survey $($ YRBS $)=0$, investigator-developed questionnaire $=1$. Whether or not the definition of drinking was specified and whether the data collectors were trained were both dummy coded as No $=0$ and Yes $=1$. The university/college type was coded as 1 = 4-year university, 2 = 3-year college, and 3 = combined results from a 3-year college and 4-year university or missing. The geographic region was coded into two moderators- east $=1$, central $=2$, and west $=3$, then south $=1$ and north $=2$-according to the classification determined by the National Bureau of Standards of China [25]. Studies conducted across more than one geographic region were coded as missing. The sample size was coded into three percentiles: $0-33$ rd percentile $=1$, 34th-66th percentile $=2$, and $>67$ th percentile $=3$.

\section{Publication bias}

Funnel plots presented visual symmetry of the outcome variables. Egger's linear regression test quantified the bias represented in the funnel plot allowing a test for significance [26].

\section{Heterogeneity}

Heterogeneity refers to the degree of between-study variance due to true effect rather than chance and is indicated as $\mathrm{I}^{2}$. A value of $0 \%$ indicates no observed heterogeneity; higher values indicated greater heterogeneity [27]. Cochran's Q-test was used to determine if the differences in outcome estimates across studies were larger than expected by chance. A significant Qvalue indicates heterogeneity.

\section{Sensitivity analysis}

To further address heterogeneity concerns a sensitivity analysis was conducted by omitting one study at a time and re-examining the overall results.

\section{Meta-analysis}

DerSimonian and Laird random effect model was used to estimate pooled drinking rates [28]. This model is recommended when it is expected that different studies will have different effects [29]. The model assigns heavier weights to larger studies [30]. 


\section{Meta-regression}

Meta-regression with maximum likelihood estimation was used to explore the effects of the moderator variables associated with the true between-study variance $\left(\mathrm{I}^{2}\right) . \mathrm{R}^{2}$ represented the between-study variance explained by the moderators. The log transformed value of ratio outcome variable was used to generate a symmetric scale with a symmetric confidence interval [31]. To ensure that the analysis would be meaningful, the recommended ratio of studies to moderators is at least 10:1 for meta-regression [29]. Considering the small numbers included in this analysis, a bivariate meta-regression was first conducted to identify which moderators may have significant effects on the logit drinking rate. The bivariate meta-regression significance level was set at .05. All the significant moderators were then included in a multiple meta-regression model to assess the relationship between multiple moderators and the logit drinking rate [29]. Since the statistical power tends to be reduced due to the small sample size of included studies, the significance level was set at $p=.1$ for the multiple meta-regression model $[10,31]$. To avoid the inflated likelihood of error in the multiple meta-regression analysis, Bonferroni correction was used to adjust the $p$ value as .033 for a three-moderators model [32].

\section{Subgroup analysis}

Subgroup analysis (analogous to analysis of variance) was applied to categorical moderators that were significantly associated with the heterogeneity identified in the multiple meta-regression analysis. The pooled drinking rate for subgroups was estimated with the random effect model. A Q-value with $p<.05$ indicates a significant group difference in last 30 day alcohol use.

Comprehensive Meta-analysis Professional Version 3 was used for the data analysis. The significance level was set at two-sided $p=.05$ for all analyses except for the multiple meta-regression analysis with adjusted significance level of $p=.03$. A list-wise deletion method was used for missing data.

\section{Results}

A total of 749 papers were initially identified through keyword search: (184 in CNKI, 207 in WF, 67 in PM, 291 in WS). Studies in WF that overlapped with studies first identified in CNKI were not counted. Similarly, studies identified in WS that had already been found in PM were not counted. Three papers reported on duplicated data and were excluded. Of the remaining 746 papers, 574 were excluded because they did not report on past 30 day alcohol use; and one study was excluded due to a confusing description of the past 30 day drinking rate. Of the remaining 171, 126 were excluded because they did not report gender-specific drinking rates. Fifteen papers that did not report Mainland China drinking studies were excluded.
The remaining 30 studies (28 in Chinese and 2 in English) were included in this analysis (Table 1). A flowchart is provided in Fig. 1 for the inclusion and exclusion process.

The funnel plots for both males and females were symmetric. Eggers's linear regression test reported a two-tailed nonsignificant $p$-value for males $(p=.889)$ and for females $(p=.488$,) indicating no publication bias (Fig. 2).

The sensitivity analyses, which involved omitting one study at a time and recalculating the overall results, suggested that for both male and female university student alcohol use were consistent, suggesting that no individual study significantly affected the findings (Fig. 3).

\section{Male university students alcohol use}

The pooled estimate of drinking among male university students in the last 30 days was $66.8 \%$, 95\% CI [62.5, 70.9] (Table 2). There was evidence of heterogeneity among the selected 30 studies $\left(\mathrm{I}^{2}=99.26 ; \mathrm{Q}=3940.25\right.$, df $=29, p<.001)$.

According to the results from the bivariate metaregression analysis, the definition of drinking, the origin of the questionnaire, and the geographic region of the survey were associated with the heterogeneity across the selected studies on the logit male drinking rate (Table 3). Surveys with stated definitions of drinking reported lower drinking rates than surveys without a stated definition $(\beta=-.8216$, $p<.01)$. The moderator of definition of drinking explained $20 \%$ of the heterogeneity. Surveys that used investigator-developed questionnaires reported higher drinking rates for males than surveys based on the more standardized YRBS questionnaire $(\beta=.9754, p<.01)$, and the moderator for questionnaire explained $21 \%$ of the heterogeneity. Surveys of central China university students reported higher drinking rates than surveys of east China university students $(\beta=1.0885, p<.01)$. Surveys of west China university students reported higher drinking rates than surveys of east China university students $(\beta=.7360$, $p<.05$ ). The moderator for geographic region (east, central, west) explained $21 \%$ of the heterogeneity.

A multiple meta-regression model was used to assess all the significant moderators in one meta-regression model. The variables of a clearly stated definition of drinking, the origin of questionnaire, and geographic region were still significant after the Bonferroni correction and explained $56 \%$ of the heterogeneity in male drinking rate.

Considering the significant effect of three categorical moderators (definition of drinking, origin of questionnaire, and geographic region) on the heterogeneity, a follow up test was performed to determine whether the pooled drinking rate for male university students differs between groups. In the subgroup analysis, the pooled drinking rate for male students was $70 \%$ using definition of alcohol drinking and $63 \%$ without definition. A 


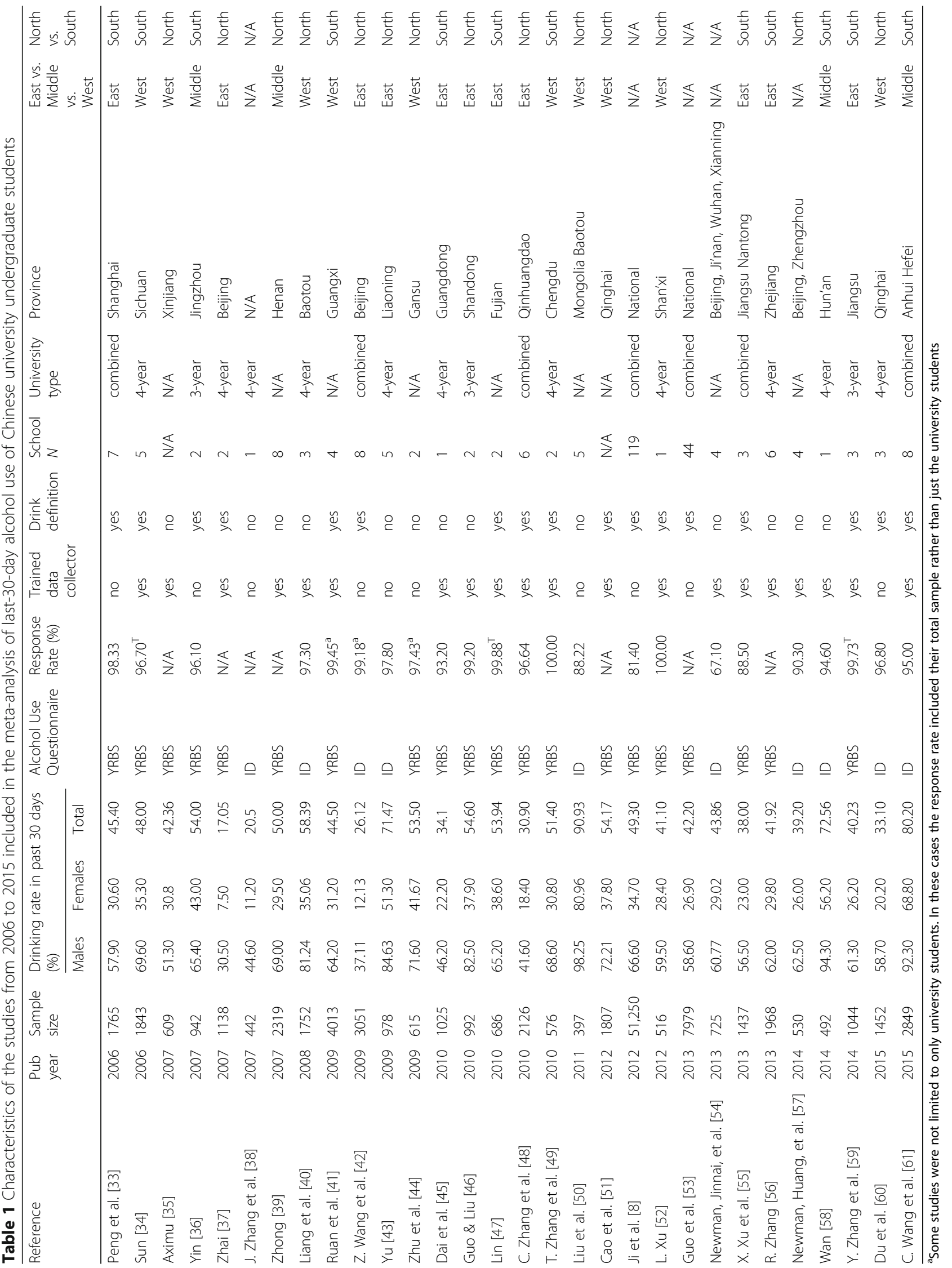


significant $Q$ value indicates a significant group difference in the logit drinking rate of males $(Q(1)=227.12$, $p<.001)$. The pooled drinking rate for male students was $64 \%$ for using YRBS questionnaire and $60.1 \%$ for using investigator-developed questionnaire. The pooled drinking rate for male students in the east, central and west regions was $52.1 \%, 74.8 \%$, and $67.5 \%$ respectively $(\mathrm{Q}(2)=1252.67$, p. $<001)$. The group difference is significant for the logit male drinking rate $(\mathrm{Q}(1)=257.30, p<.001)$ (Table 4$)$.

\section{Female university students alcohol use}

The pooled estimates for the drinking rate in the past 30 days among female university students was $31.7 \%$, 95\% CI [27.8, 35.8] (Table 2). There is evidence of heterogeneity $\left(\mathrm{I}^{2}=99.19, \mathrm{Q}=3566.0, \mathrm{df}=29, p<.001\right)$ among reported drinking rates.

According to the results of the bivariate megaregression analysis, the definition of drinking, the origin of the questionnaire, and the geographic region of the survey were associated with the heterogeneity across the selected studies on the logit female drinking rate (Table 3). Surveys with stated definitions of drinking reported lower drinking rates than surveys without a stated definition $(\beta=-.5670$, $p<.05)$. The moderator of definition of drinking explained $14 \%$ of the heterogeneity. Surveys that used investigator-developed questionnaires reported higher drinking rates than surveys based on the more standardized YRBS questionnaire $(\beta=.5892, p<.05)$, and the moderator for questionnaire explained $12 \%$ of the heterogeneity. Surveys of central China university students reported higher drinking rates than surveys of east China university students $(\beta=.8886, p<.01)$. Surveys of west China university students reported higher drinking rates than surveys of east China university students $(\beta=.6017$, $p<.05$ ). The moderator for geographic region (east, central, west) explained $22 \%$ of the heterogeneity.

Results from the multiple meta-regression analysis indicated that only the variable 'a stated definition of

A total of 749 non-unique studies between 2006 and 2015 on

Chinese undergraduate university student drinking were

identified in four electronic databases:

Two Chinese databases $(\mathrm{CNKI}=184$, WanFang=207)

Two English databases (PubMed=67, Web of Science=291)

3 papers excluded because of

duplicated data

746 unique papers

574 papers excluded because no last

30 day drinking rate reported and 1

for a confusing description of the past

30 days drinking rate

171 unique papers

126 papers excluded because no genderspecific drinking rates reported

45 unique papers

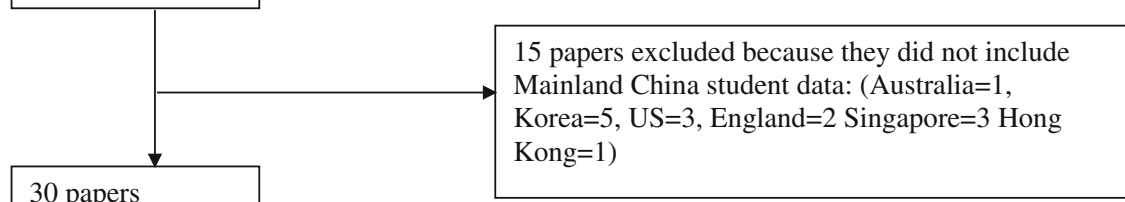

30 papers

included in the

meta-analysis

Fig. 1 Flowchart of study selection, inclusion and exclusion for surveys of Chinese university student past-30-day alcohol use, 2006-2015. CNKI = China National Knowledge Infrastructure, WF = Wanfang, PM = PubMed, WS = Web of Science 
alcohol drinking' is significant after the Bonferroni correction, and this variable explained $47 \%$ of the heterogeneity.

A subgroup analysis was applied to the significant categorical variable of definition identified in the metaregression analysis. In the subgroup analysis, the pooled drinking rate for female students was $42.5 \%$ using definition of alcohol drinking and $32.2 \%$ without definition. A significant $Q$ value indicates significant group difference $(\mathrm{Q}(1)=492.86, p<.001)$ (Table 4$)$.

\section{Discussion}

This meta-analysis provided an estimate of Chinese undergraduate university student drinking rates in the last 30 days of $66.8 \%$ for male university students and $31.7 \%$ for female university students. As expected, the estimated drinking rate is higher for males than for females. While many papers on alcohol use by university students have been published, this is the first to present an estimate of last 30 day drinking rates based on surveys of Mainland China undergraduate university

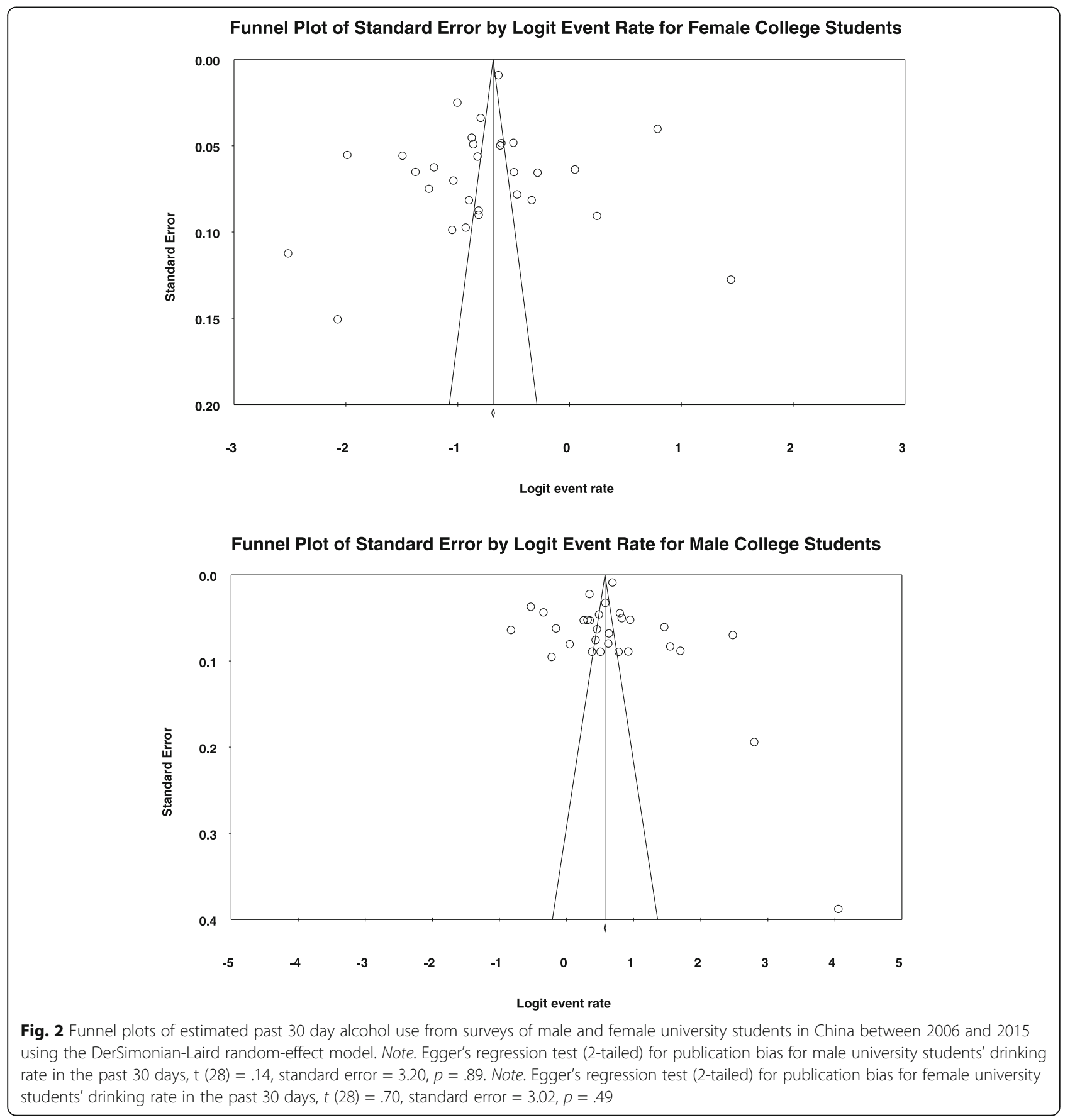


Leave-one-out Summary and Forest Plot for Male College Students

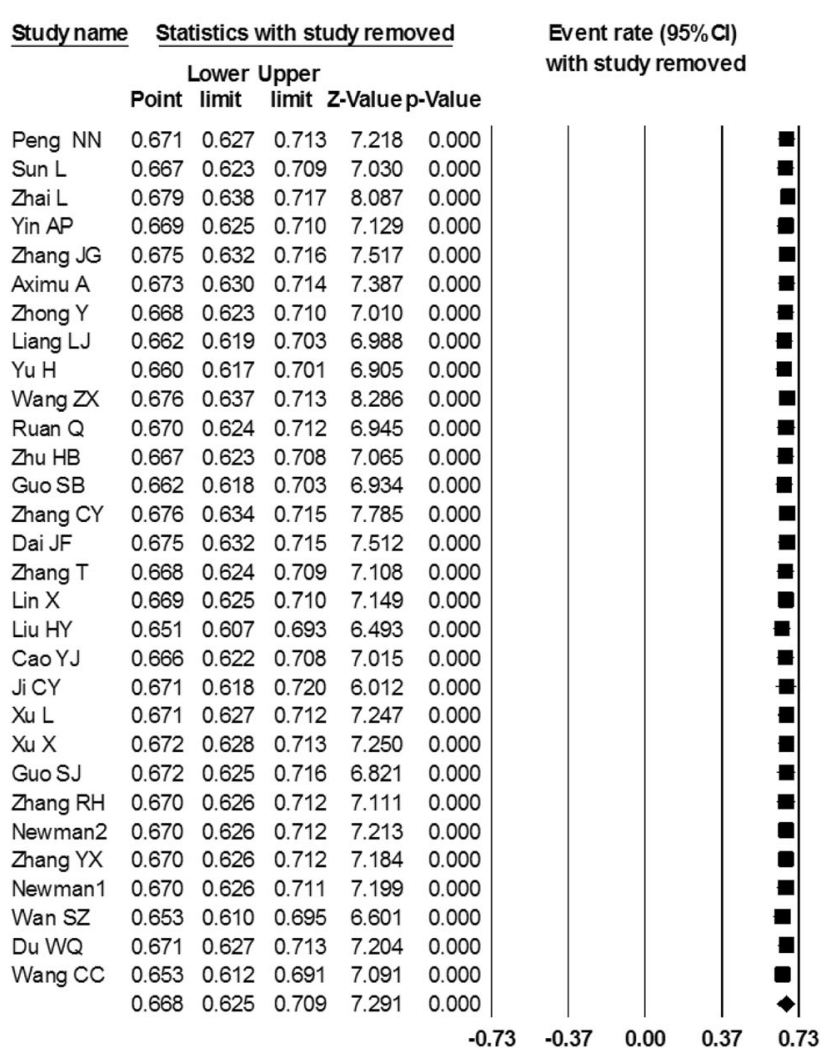

Leave-one-out Summary and Forest Plot for Female College Students

\begin{tabular}{|c|c|}
\hline Study name & Statistics with study removed \\
\hline
\end{tabular}
Point limit limit Z-Valuep-Value

$\begin{array}{llllll}\text { Peng NN } & 0.317 & 0.277 & 0.359 & -7.947 & 0.000\end{array}$

$\begin{array}{llllll}\text { Sun L } & 0.315 & 0.276 & 0.358 & -7.979 & 0.000\end{array}$

$\begin{array}{llllll}\text { Zhai L } & 0.329 & 0.291 & 0.370 & -7.731 & 0.000 \\ \text { Yin } & 0.313 & 0.274 & 0.355 & -8.209 & 0.000\end{array}$

$\begin{array}{llllll}\text { Yin AP } & 0.313 & 0.274 & 0.355 & -8.209 & 0.000\end{array}$

$\begin{array}{llllll}\text { Zhang JG } & 0.326 & 0.286 & 0.367 & -7.722 & 0.000\end{array}$

$\begin{array}{llllll}\text { Aximu A } & 0.317 & 0.278 & 0.359 & -8.019 & 0.000 \\ \end{array}$

$\begin{array}{llllll}\text { Zhong Y } & 0.317 & 0.277 & 0.360 & -7.876 & 0.000\end{array}$

Liang LJ $\quad 0.315 \quad 0.276 \quad 0.358 \quad-7.982 \quad 0.000$

$\begin{array}{lllllll}\text { YuH } & 0.310 & 0.272 & 0.351 & -8.438 & 0.000\end{array}$

$\begin{array}{llllll}\text { Wang ZX } & 0.326 & 0.289 & 0.365 & -8.171 & 0.000\end{array}$

$\begin{array}{llllll}\text { Ruan Q } & 0.317 & 0.276 & 0.360 & -7.752 & 0.000\end{array}$

$\begin{array}{llllll}\text { Zhu HB } & 0.313 & 0.274 & 0.355 & -8.199 & 0.000\end{array}$

$\begin{array}{llllll}\text { Guo SB } & 0.314 & 0.275 & 0.356 & -8.098 & 0.000\end{array}$

\begin{tabular}{llllll} 
Zhang $\mathrm{CY}$ & 0.322 & 0.283 & 0.363 & -7.931 & 0.000 \\
\hline
\end{tabular}

$\begin{array}{llllll}\text { Dai JF } & 0.320 & 0.281 & 0.362 & -7.902 & 0.000\end{array}$

\begin{tabular}{lllllll}
\hline Zhang T & 0.317 & 0.278 & 0.359 & -8.022 & 0.000
\end{tabular}

$\begin{array}{lllllll}\text { Lin } X & 0.314 & 0.275 & 0.356 & -8.136 & 0.000\end{array}$

$\begin{array}{lllllll}\text { Liu HY } & 0.301 & 0.265 & 0.340 & -9.188 & 0.000\end{array}$

$\begin{array}{llllll}\text { Cao YJ } & 0.314 & 0.275 & 0.357 & -8.029 & 0.000\end{array}$

$\begin{array}{lllllll}\mathrm{JiCY} & 0.315 & 0.267 & 0.368 & -6.429 & 0.000\end{array}$

$\begin{array}{llllll}\text { Xu L } & 0.318 & 0.278 & 0.360 & -7.993 & 0.000 \\ X_{u} \mathrm{X} & 0.32 & 0.281 & 0.362 & -7.901 & 0.000\end{array}$

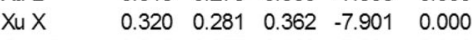

$\begin{array}{lllllll}\text { Guo SJ } & 0.318 & 0.277 & 0.362 & -7.581 & 0.000\end{array}$

$\begin{array}{lllllll}\text { Zhang RH } & 0.317 & 0.277 & 0.360 & -7.903 & 0.000 \\ & 0.37 & 0.278 & 0.359 & -7.98 & 0.000\end{array}$

$\begin{array}{llllll}\text { Newman2 } & 0.317 & 0.278 & 0.359 & -7.986 & 0.000\end{array}$

$\begin{array}{lllllll}\text { Zhang YX } & 0.319 & 0.279 & 0.361 & -7.934 & 0.000\end{array}$

$\begin{array}{llllll}\text { Newman1 } & 0.319 & 0.279 & 0.361 & -7.960 & 0.000\end{array}$

$\begin{array}{llllll}\text { Wan SZ } & 0.309 & 0.271 & 0.350 & -8.523 & 0.000\end{array}$

$\begin{array}{llllll}\text { Du WQ } & 0.321 & 0.282 & 0.363 & -7.896 & 0.000\end{array}$

$\begin{array}{llllll}\text { Wang CC } & 0.305 & 0.274 & 0.338 & -10.656 & 0.000\end{array}$ $\begin{array}{lllll}0.317 & 0.278 & 0.358 & -8.219 & 0.000\end{array}$

$\begin{array}{llllll}-0.37 & -0.19 & 0.00 & 0.19 & 0.37\end{array}$

Fig. 3 Sensitivity analysis summary and forest plots for Chinese university student drinking surveys from 2006 to 2015 using the DerSimonian-Laird random-effect model

students, published in English or Chinese, and describing male and female alcohol use separately. The results reflect the best estimate of last-30-day alcohol use by Chinese undergraduate university students.

This estimate for university students' alcohol use is higher than WHO's estimates of per capita drinking in the previous year for persons 15 years and older in China: $58.4 \%$ male, $28.9 \%$ females [1,2]. We will refrain from offering explanations of why university undergraduate student drinking rates appear to be higher than adult per capita drinking rates. That question is beyond the scope of this analysis.

This estimate for university students' alcohol use is also higher than the last 30 day drinking rates estimated

Table 2 Pooled estimates of drinking in the past 30 days for male and female university students, data from China 2006-2015

\begin{tabular}{|c|c|c|c|c|c|c|c|c|}
\hline \multirow[t]{2}{*}{ Subgroup } & \multirow[t]{2}{*}{$N$} & \multicolumn{2}{|c|}{ Rate range (\%) } & \multirow{2}{*}{$\begin{array}{l}\text { Pooled } \\
\text { rate (\%) }\end{array}$} & \multicolumn{2}{|c|}{$95 \% \mathrm{Cl}$} & \multirow[t]{2}{*}{ Q } & \multirow[t]{2}{*}{$P^{2}(\%)$} \\
\hline & & $\mathrm{LL}$ & UL & & $\mathrm{LL}$ & UL & & \\
\hline Iale & 30 & 30.50 & 98.25 & 66.8 & 62.5 & 70.9 & $3940.25^{* * *}$ & 99.26 \\
\hline Female & 30 & 7.5 & 80.96 & 31.7 & 27.8 & 35.8 & $3566.0^{* * *}$ & 99 \\
\hline
\end{tabular}

$C l$ confidence interval, $L L$ lower limit, UL upper limit

${ }^{* * * *} p<.001$ for the Cochrane $Q$ test for high school students: $36.5 \%$ males and $22.2 \%$ females attending regular high schools, and $44.7 \%$ males and $28.8 \%$ females attending vocational high schools [10]. The significant differences between high school drinking rates and the university student drinking rates could be a direct result of the way Chinese high school students focus on preparation for the university entrance examination (known as the gaokao).

Studies of Chinese high school students' drinking have found that vocational high school students report higher drinking rates than regular high school students [10]. One of the main differences between the two types of high school students is that regular high school students are preparing for the gaokao, while the vocational high school students typically are not. Preparation for the gaokao is rigorous and begins before the last year of high school. Students pressure themselves to a strict discipline of study, reinforced and supervised by parents and teachers. There is little time for any recreational activities. By comparison the vocational high school students have more discretionary time to be involved in activities that include alcohol. Once high school students have finished the gaokao and have been accepted to universities, 
Table 3 Moderators associated with the heterogeneity of past-30-day drinking rate estimates in surveys of Chinese university students, 2006-2015

\begin{tabular}{|c|c|c|c|c|c|c|c|}
\hline Outcome variables & Moderators & Bivariate $\beta$ & SE & $\mathrm{R}^{2} \%$ & Multiple Meta-regression $\beta$ & SE & $\mathrm{R}^{2} \%$ \\
\hline \multicolumn{8}{|c|}{ Logit drinking rate of males } \\
\hline & Definition (yes $=1$, no $=0$ ) & $-.8216^{* *}$ & .3060 & 20 & $-.7886^{* *}$ & .297 & 56 \\
\hline & Questionnaire $($ YRBS $=0$, Investigator-developed $=1)$ & $.9754^{* *}$ & .3492 & 21 & $.8795^{* *}$ & .341 & \\
\hline & Region (east to central) & $1.0885^{* *}$ & .4817 & 21 & $.711^{*}$ & .3762 & \\
\hline & Region (east to west) & $.7360^{*}$ & .4021 & & $.6184^{*}$ & .317 & \\
\hline \multicolumn{8}{|c|}{ Logit drinking rate of females } \\
\hline & Definition (yes $=1$, no $=0$ ) & $-.5670^{*}$ & .2595 & 14 & $-.6633^{* *}$ & .2703 & 47 \\
\hline & Questionnaire $($ YRBS $=0$, Investigator-developed $=1$ ) & $.5892^{*}$ & .3018 & 12 & .3919 & .2975 & \\
\hline & Region (east to central) & $.8886^{* *}$ & .3744 & 22 & .5847 & .3302 & \\
\hline & Region (east to west) & $.6017^{*}$ & .3121 & & .5242 & .2747 & \\
\hline
\end{tabular}

${ }^{* *} p<.01,{ }^{*} p<.05$ for bivariate regression. Bonferroni correction applied on the significance level of .1 for multiple meta-regression analysis: the significance level $=.1 / 3=.033$ for 3 moderators

they are under much less pressure and have more freedom to engage in activities that could include alcohol. In this manner the gaokao may be protective for high school students by delaying their drinking until they enter university. There are likely other individualspecific explanations for these rates that have not been identified and studied.

The university student drinking rates need to be interpreted in the context of Chinese university life and Chinese alcohol culture. China is a relationship society, meaning the social structure is based first on relationships. Actions that build, maintain and protect relationships are important, and sharing alcohol is an important part of this process. Alcohol use in moderation is considered good for health, it is a part of meals, ceremonies and celebrations, and it is an important part of Chinese medicine. It is legal for university students to purchase and consume alcohol. Chinese universities, with the exception of the newest campuses, are walled compounds with everything inside the walls that students need: housing, recreational facilities, food services, health services, educational services, post offices, small shops and banks. During the week there is little need to leave the campus. On weekends students will often go off-campus with friends to eat a lunch or dinner at local restaurants. Eating with friends is a typical occasion for drinking alcohol, usually beer. In this context, the last30-day rates reported here are not surprising and do not necessarily represent high risk drinking.

The moderator analysis showed that the heterogeneity observed affected the results, and the significant $\mathrm{I}^{2}$ suggests caution in interpreting these results. Nine moderator variables were examined in the meta regression, and three of the moderators should be considered in interpreting these results: whether the survey stated a definition of drinking, whether the questionnaire was

Table 4 Pooled estimates for subgroups using DerSimonian-Laird Random-Effect Model for Chinese university students' past-30-day alcohol use, 2006-2015

\begin{tabular}{|c|c|c|c|c|c|c|}
\hline Outcome variable & Subgroup & $N$ & Pooled estimate(\%) & $95 \% \mathrm{Cl}$ & $1^{2}$ & $\overline{Q_{\text {between }}}$ \\
\hline \multicolumn{7}{|c|}{ Pooled male drinking rate } \\
\hline & Definition (no) & 13 & 70.0 & $69.2-70.8$ & 99.17 & \multirow[t]{2}{*}{$227.12^{* * *}$} \\
\hline & Definition (yes) & 17 & 63.0 & $62.7-63.4$ & 99.31 & \\
\hline & Questionnaire: (YRBS) & 21 & 64.0 & $63.7-64.3$ & 98.84 & \multirow[t]{2}{*}{$257.30^{* * *}$} \\
\hline & Investigator-developed & 8 & 60.1 & $59.0-61.3$ & 99.64 & \\
\hline & Region east & 11 & 52.1 & $51.3-52.9$ & 99.29 & \multirow[t]{3}{*}{$1252.67^{* * *}$} \\
\hline & Region middle & 5 & 74.8 & $73.7-75.9$ & 99.35 & \\
\hline & Region west & 9 & 67.5 & $66.6-68.3$ & 97.92 & \\
\hline \multicolumn{7}{|c|}{ Pooled female drinking rate } \\
\hline & Definition (no) & 13 & 42.5 & $41.6-43.4$ & 99.26 & \multirow[t]{2}{*}{$492.86^{* * *}$} \\
\hline & Definition (yes) & 17 & 32.2 & $31.9-32.5$ & 98.89 & \\
\hline
\end{tabular}


based on YRBS or was investigator developed, and the geographic region where the data were collected.

\section{Definition of drinking}

A clearly stated definition of drinking as having "at least one cup" of an alcohol beverage (yes vs. no) was associated with the logit drinking rates of male and female university students. Surveys with stated definitions of drinking reported lower drinking rates compared to surveys without definitions (Table 4). This finding is similar to one reported in an earlier meta-analysis of high school student drinking rates [10]. In published studies of Chinese alcohol use, surveys have used drinking self-report for the past week, past 30 days, past 3 months, past 6 months, past year, and lifetime. Even in surveys that specify the past 30 days, alcohol questions differ on the basis of quantity. Some questions ask if a respondent has drunk alcohol at least once, including one sip, some questions specify at least one cup. Specificity has its value in quantifying a behavior, but it is also possible that specificity overlooks important drinking patterns that deserve attention. There is a need for a standardized definition of alcohol drinking to improve the accuracy of estimating drinking rates [9]. This standardized definition needs to be based on a careful observation of actual student drinking behaviors within Chinese alcohol culture.

\section{Questionnaire development}

Logit drinking rates for males were related to whether or not the questionnaire was developed by the investigator or based on YRBS. Studies that used YRBS-based questionnaires reported higher drinking rates for males compared to studies using investigator-developed questionnaires. There was no significant difference in female last-30-day drinking based on type of questionnaire (Table 4). We believe men's drinking tends to be more nuanced, with drinking varying according to traditional, established protocols regarding appropriate drinking for the time, place, occasion, and companions. In China, women drinking in public is relatively new. That is not to say that women did not drink on many occasions out of public view, often only in the company of other women; however, these occasions tended to be traditional functions like rites of passage, lunar festivals, and other special ceremonies where drinking occurred as part of the ceremony. Now there is a wider acceptance of women drinking in public, an awareness of more female drinking, and an acknowledgement of female-only drinking occasions. The relative newness of acceptability of female drinking may mean its repertoire is limited and either type of questionnaire captures the behavior equally well. Men's drinking behavior, while superficially standardized, because it is so widespread and so integrated into daily life may be better captured by investigator-developed questionnaires than by the more standardized (restricted) YRBS-type alcohol use questions.

The most likely variations in questionnaire development that affect these differences relate to 1) how alcohol is defined, 2) how quantity is measured, and 3) how frequency is measured, and 4) the way Western questions are translated into Chinese.

\section{Definition of "alcohol"}

In the West, alcohol questionnaires are generally organized around three types of alcohol: beer, wine, and spirits. In China, the classification of alcohol types is more complicated: there are more types of beverage alcohol and there is no widely accepted understanding of a standard drink. Beer is comparable, with beer strength and packaging being fairly similar in China and the West. In China "wine" can mean fruit wines (often imported, Western-style strength and packaging), but it also refers to traditional wines such as huangjiu (yellow wine, common in the Shanghai area) or low strength rice wines and porridges. Distilled spirits are popularly classified by the grains used to make them and by their strength (high-strength spirits and low-strength spirits, with about $40 \%$ alcohol-by-volume being the threshold). Locally-made varieties of unlabeled, unrecorded spirits are legal, inexpensive and readily available, especially in rural areas [17]. Medicinal spirits (distilled spirits compounded with plant and animal ingredients) are part of Chinese traditional medicinal. In addition, there is little understanding of how much wine is used in traditional Chinese cooking, and whether the cooking methods ensure that the alcohol is fully reduced before the food is eaten. To accommodate this wider range of beverage alcohols, some large surveys of Chinese alcohol use have included questions on as many as five beverage alcohol categories (but not medicinal spirits) $[3,18]$.

\section{Quantity}

Alcohol survey questions ask if a respondent has drunk alcohol at least once "including one sip," some questions specify "at least one cup." There is an absence of a widely accepted understanding of a "standard drink" both in terms of the drinking cup size and the beverage container size. Beer is sold in reasonably uniform-sized containers, ranging from $300 \mathrm{ml}$ to $1 \mathrm{~L}$, so survey data on beer consumption can probably provide useful information on quantity. Fruit wine (especially imported wine) is often in standard bottles and served in wine glasses; however, wine currently makes up less than $3 \%$ of alcohol consumed in China [2]. Spirits are sold in containers of varied sizes. Spirits are often served in cups, glasses and bowls of different sizes and shapes that are frequently topped up by others in the drinking group, making it difficult to estimate quantity consumed. 
Even a simple survey question defining alcohol as "more than one cup" can be interpreted many ways. In terms of trying to estimate alcohol consumption in terms of liters of pure alcohol, it should be noted that Chinese spirits come in a wide range of strengths.

\section{Translating survey questions}

Translating Western alcohol survey questions is challenging, and the accuracy of the translation directly affects the validity of the data collected. There are many Chinese words for different types of alcohol. In everyday conversation "wine" (jiu, 酒) is used as a generic term for all types of alcohol. Beer is sometimes not thought of, by survey respondents, as a form of alcohol. Because alcohol use, even by very young people, is an unremarkable event, especially at festivals, unless carefully specified in the questionnaire many drinking events may be overlooked by respondents when answering questions about alcohol use.

These wide-ranging concerns about questionnaire development may explain the differences in rates reported in studies that used investigator-developed questionnaires and studies that used YRBS-based questionnaires.

\section{Geographic Region}

The moderator geographic region (east vs. central, east vs. west) was associated with the logit drinking rates for male university students. Surveys of students at central China universities reported higher drinking rates. Surveys of students at eastern China universities reported lower drinking rates, and surveys in western China reported drinking rates in between.

A meta-analysis of studies of high school student alcohol use also found higher drinking rates were reported from surveys of west China adolescents. That metaanalysis of high school surveys found surveys from central China reported lower drinking rates, and surveys from eastern China were in between [10]. Neither the meta-analysis of high school drinking studies [10] or this meta-analysis of university drinking studies showed any significant north-south differences.

Because high schools enroll local adolescents, we expected to find some geographic differences that reflected regional differences in alcohol use. Universities, on the other hand, especially the more prestigious universities, serve students from all parts of the country, so accounting for differences due to the geographic region of the survey is more difficult.

The very suggestion of drinking rates varying at universities in different regions of the country begs exploration, as does the effect of geographic region on male drinking but not on female drinking. Geographic differences in drinking rates in a country as large and diverse as China calls into question the usefulness of national drinking rate estimates in alcohol policy development.

\section{Limitations}

Many technical issues, not assessed in this analysis, could have affected the results. Survey research is relatively new in China and surveys of populations like university students are often conducted by wellmeaning investigators with little experience. We have no information on the conditions under which the data were gathered, how confidentiality was assured, how any assurance of anonymity was interpreted or the methods used for data collection. We have no information on how the samples were identified and how individuals who completed surveys were recruited. We have no information on the times of the year the surveys were conducted. Timing could have affected survey results if data were collected within 30 days of significant festivals, rites of passage and other significant events in which alcohol is a traditional part. The diversity of the students in the samples represented in these papers may not have been truly representative of the Chinese university student population. We know little about data management and analysis techniques used in the studies included in this analysis.

\section{Conclusions}

This meta-analysis of 30 studies published in Chinese and English between 2006 and 2015 of self-reported alcohol use by Chinese undergraduate university students (approximate age 18-23 years old) provided an estimate alcohol use in the last 30 days of $66.8 \%$ for males and $31.7 \%$ for females.

\section{Abbreviations}

ANOVA: Analysis of variance; CNKI: China National Knowledge Infrastructure (database); PM: PubMed (database); WF: Wanfang (database); WHO: World Health Organization; WS: Web of Science (database); YRBS: Youth Risk Behavior Surveillance Survey

\section{Acknowledgements}

Rafael DeAyala, Chair of the Department of Educational Psychology at the University of Nebraska-Lincoln, provided valuable advice at the beginning of the project. Michelle Maas assisted in manuscript preparation and provided valuable critique throughout the project. Duane F. Shell, Research Professor in the Department of Educational Psychology, University of Nebraska-Lincoln reviewed drafts of the manuscript and contributed valuable edits.

\section{Funding}

This research was not funded.

\section{Availability of data and materials}

Not applicable.

\section{Authors' contributions}

IN and YF designed the study. LD conducted the literature search. LD carried out the statistical tests and prepared the first draft of the manuscript. IN and YF made critical revisions to the first draft and prepared the final draft of manuscript. All authors read and approved the final version. 


\section{Ethics approval and consent to participate}

Not applicable.

\section{Consent for publication}

Not applicable.

\section{Competing interests}

Lanyan Ding and Yonghua Feng have no competing interests to declare. Prior to 2014 lan Newman was a member of the Research Advisory Committee of the International Center for Alcohol Policies, Washington, D.C. prior to 2014 he received fees and travel support to attend meetings sponsored or $\mathrm{CO}^{-}$ sponsored by the International Center for Alcohol Policies. Prior to 2013 lan Newman consulted for the National Health Education Institute, Chinese CDC, Chinese Center for Health Education (CCHE). In the past 5 years, he has received University of Nebraska employment-related funding from the U.S. Department of Education, the Nebraska Department of Health and Human Services, the Nebraska Department of Roads/Nebraska Office of Highway Safety. As American deputy director of the American Exchange Center at Xi'an Jiaotong University, Newman received funds from the US State Department and the University of Nebraska. Ian Newman owns an equity interest in The Buffalo Beach Company (Lincoln, Nebraska) and has received consulting fees from The Buffalo Beach Company for independent research related to indigenous alcohol use and traffic safety.

\section{Publisher's Note}

Springer Nature remains neutral with regard to jurisdictional claims in published maps and institutional affiliations.

Received: 26 May 2017 Accepted: 11 July 2017

Published online: 11 December 2017

\section{References}

\section{*References marked with an asterisk indicate studies included in the} meta-analysis

1. World Health Organization. Global Status Report on Alcohol and Health 2014. Geneva: WHO; 2014. Retrieved from http://apps.who.int/iris/bitstream/10665/112736/1/9789240692763_eng.pdf. Accessed 02 February 2017.

2. World Health Organization, Global Information System on Alcohol and Health (GISAH). China (country profile). Available from http://www.who.int/substance_abuse/publications/global_alcohol_report/ profiles/chn.pdf . Accessed 02 February 2017.

3. Millwood IY, Li L, Smith M, Guo Y, Yang L, Bian Z, Lewington S, Whitlock G, Sherliker P, Collins R, Chen J, Peto R, Wang H, Xu J, He J, Yu M, Liu H, Chen Z. Alcohol consumption in 0.5 million people from 10 diverse regions of China: prevalence, patterns and socio-demographic and health-related correlates. Int J Epidemiol. 2013:42(3):615-27.

4. UNC Carolina Population Center. China Health and Nutrition Survey household and individual data. Available from

http:/www.cpc.unc.edu/projects/china/data/datasets. Accessed 02 February 2017.

5. Peking University. China Health and Retirement Longitudinal Survey (CHARLS) data. Available for English users from http://forum.charls.org/. Accessed 02 Feb 2017

6. World Health Organization. WHO Study on global ageing and adult health (SAGE) data archive. Available from http://www.who.int/healthinfo/sage/en/. Accessed 02 Feb 2017.

7. Ma SB, Kong LZ. Nutrition and Health Situation Survey Among Chinese Residents: Research Report No. 9 Behavior and Lifestyle. Beijing: Renmin Weisheng Chubanshe [People's Medical Publishing House]; 2006. [in Chinese]

8. $* \mathrm{Ji} \mathrm{CY}, \mathrm{Hu} \mathrm{PJ}$, Song Y. The epidemiology of alcohol consumption and misuse among Chinese college students. Alcohol Alcohol. 2012;47(4):464-72.

9. Newman IM, Qian L, Xue JP. College student alcohol surveys: The need for uniform questions. Zhongguo Yaowu Lanyong Fangzhi Zazhi. 2004;10(5):272-5.

10. Feng $Y$, Newman IM. Estimate of adolescent alcohol use in China: a metaanalysis. Arch Public Health. 2016;74(1):45.

11. Baer JS, Kivlahan DR, Marlatt GA. High-risk drinking across the transition from high school to college. Alcohol Clin Exp Res. 1995;19:54-61.

12. China National Knowledge Infrastructure database (CNKI). http:IIwww.cnki.net. 02 Feb 2017.
13. Wanfang database. http:IIwww.wanfangdata.com.cn. 02 Feb 2017.

14. PubMed database. http:IIwww.ncbi.nlm.nih.gov/pubmed/advanced. 02 Feb 2017.

15. Web of Science database. http:\lwww.webofknowledge.com. 02 Feb 2017

16. Hammersley R. A digest of memory phenomena for addiction research. Addiction. 1994;89(3):283-93.

17. Qian L, Newman IM, Xiong W, Feng YY. Traditional grain alcohol (bai jiu, 白 酒) production and use in rural central China: implications for public health. BMC Public Health. 2015;15:1261. doi: 10.1186/s12889-015-2594-4

18. Lu S, Du S, Hu X, Zou S, Liu W, Ba L, Ma G. Drinking patterns and the association between socio-demographic factors and adolescents' alcohol use in three metropolises in China. Int J Environ Res Public Health. 2015;12(2): 2037-53.

19. He J, Assanangkornchai S, Cai L, McNeil E. Patterns of alcohol consumption in Yunnan Province in China: which measure is optimal? Alcohol Alcohol. 2015:50(5):579-87.

20. Li Y, Jiang Y, Zhang M, Yin P, Wu F, Zhao W. Drinking behavior among men and women in China: the 2007 China Chronic Disease and Risk Factor Surveillance. Addiction. 2011;106:1946-56.

21. Zhang X, Liu F. Analysis of the drinking status among college students and the influencing factors. Xian dai yu fang yi xue [Modern preventive medicine]. 2008;35(3):534-6.

22. Quality Assessment of Systematic Reviews and Meta-Analyses (NIH) https://www.nhlbi.nih.gov/health-pro/guidelines/in-develop/cardiovascularrisk-reduction/tools/sr_ma 02 Feb 2017.

23. Groves RM, Lyberg L. Total survey error: Past, present, and future. Public Opin Q. 2010;74(5):849-79.

24. Moher D, Jadad AR, Nichol G, Penman M, Tugwell P, Walsh S. Assessing the quality of randomized controlled trials: an annotated bibliography of scales and checklists. Control Clin Trials. 1995;16(1):62-73.

25. National Bureau of Statistics of China. The method of categorizing east, central, and west, as well as north and south [in Chinese]. 2011. Retrieved from http://www.stats.gov.cn/ztic/zthd/sjtir/dejtjkfr/tjkp/201106/t20110613 71947. htm. 02 Feb 2017

26. Egger M, Smith GD, Schneider M, Minder C. Bias in meta-analysis detected by a simple, graphical test. BMJ. 1997;315(7109):629-34.

27. Higgins J, Thompson SG, Deeks JJ, Altman DG. Measuring inconsistency in meta-analyses. BMJ. 2003;327:557-60.

28. DerSimonian R, Laird N. Meta-analysis in clinical trials. Control Clin Trials. 1986;7(3):177-88.

29. Borenstein M, Hedges LV, Higgins J, Rothstein HR. A basic introduction to fixed-effect and random-effects models for meta-analysis. Res Synth Methods. 2010;1(2):97-111.

30. Hedges LV, Olkin O. Tests of statistical significance of combined results. In: Hedges LV, Olkin O, editors. Statistical Methods for Meta-Analysis. San Diego: Academic; 1985. p. 28-46.

31. Borenstein M, Hedges LV, Higgins J, Rothstein HR. References, in Introduction to Meta-Analysis. Chichester: John Wiley \& Sons, Ltd; 2009. doi: 10.1002/9780470743386.refs.

32. Armstrong RA. When to use the Bonferroni correction. Ophthalmic Physiol Opt. 2014;34(5):502-8

33. *Peng N, Zhu J, Zhou Y, Gao G, Zhu W, Luo C. The status of addiction to tobacco and alcohol in college students in Shanghai [in Chinese]. Chin J Sch Doctor. 2007;20(4):339-42.

34. *Sun L. Analysis of health risk behaviors of urban adolescents in Sichuan [in Chinese]. Chin J Sch Health. 2006;27(12):1069-72.

35. ${ }^{*}$ Aximu A. Investigation on smoking and drinking behavior among adolescents in 3 cities of Xinjiang [in Chinese]. Chin J Sch Health. 2007;28(4):325-6.

36. *Yin A. Logistic regression analysis of drinking status and related factors of college students [in Chinese]. Chin Pract Med. 2007;2(25):23-5.

37. *Zhai L. Health risk behaviors of 1138 college students in Beijing [in Chinese]. Chin J Sch Health. 2007;28(3):264-6.

38. *Zhang J, Merrick T, Newman IM, Qian L. Reaction of college students to facial flushing caused by drinking [in Chinese]. Chin J Health Educ. 2007; 4(23):271-4.

39. *Zhong Y. Study on adolescents' smoking, drinking and drug addiction behavior in Henan Province [in Chinese]. Chin J Sch Doctor. 2007:21(5): 496-8. 
40. * *Liang L, Tian J, Xu W, Wang Y, An J, Ma N. Investigation on drinking behavior of college students in Baotou City, Inner Mongolia, China [in Chinese]. Chin J Dis Cont Prev. 2008;12(6):601-3.

41. *Ruan Q, Liu X, Dong Y, Chen H. Status of health risk behavior among adolescents in Guangxi [in Chinese]. Chin J Occup Health. 2009;25(24):2666-9.

42. *Wang Z, Zhang Q, Ma Y, Xu R, Wu S, Zhang J, Li X. Investigation on smoking, drinking and physical exercises among college students and postgraduates in different types of universities in Beijing [in Chinese]. Chin J Sch Health. 2009;30(6):499-501.

43. ${ }^{*} \mathrm{Yu} \mathrm{H}$. Investigation on unhealthy behavior of college students [in Chinese]. Bull Sports Sci Technol. 2009;17:77-6.

44. *Zhu H, Li J, Wang Y, Tian Y, Hu F. Prevalence of adolescent health risk behaviors in Zhangye City [in Chinese]. Chin J Sch Health. 2009;30(12):1133-5.

45. *Dai J, Wang S, Wang C, Zhao G, Dong X. Logistic regression analysis of adverse health behaviors and risk factors among college students [in Chinese]. Chin J Dis Contr Prev. 2010;14(10):953-5.

46. ${ }^{*}$ Guo S, Liu L. Investigation on smoking and drinking behavior of college students in Heze City [in Chinese]. J Baotou Med Coll. 2010;26:323-4.

47. * Lin X. The analysis of youth risky behaviors in Fuzhou [in Chinese]. Chin J Sch Health. 2010;31(3):355-7.

48. *Zhang C, Fang L, Yuan Y, Li H, Bai R, Chi X, Yang X, Zhao X. Analysis on health risk behaviors of college students in different types of colleges in Qinhuangdao [in Chinese]. Chin J School Doctor. 2010;24(8):561-3.

49. *Zhang T, Li M, Liu Y, Ju Y, He C. Investigation on health-related behaviors of freshmen in Chengdu [in Chinese]. Chin J Occup Health Inj. 2010;25(3): 138-41.

50. * Liu H, Yang M, Na B, Wang Z, Ying K. Investigation and analysis on smoking and drinking status of Mongolian college students [in Chinese]. Technol Pioneers. 2011;9:312-5.

51. ${ }^{*}$ Cao Y, Ji H, Guo X, Guo W. A survey of smoking, drinking and gambling addiction among students in Qinghai Plateau Area [in Chinese]. Chin J Sch Health. 2012;33(4):398-9.

52. *Xu L. Investigation on health risk behaviors of medical college students. Clin Med Pract. 2012;21(5):331-3.

53. *Guo S, Yu X, Zhang X, An W, Guo L, Wang J. Analyzing the aggregation of health risk behaviors of college students such as smoking and drinking [in Chinese]. J Peking Univ (Health Science). 2013;45(3):382-6.

54. *Newman IM, Jinnai I, Zhao J, Huang Z, Pu J, Qian L. Social meaning of alcohol-related flushing among university students in China. Asia Pac J Public Health. 2013;25(5):409-19.

55. *Xu X, Zhu X, Zhu Q, He N, He M, Yin M. The current situation of smoking, drinking and substance use among college students in Nantong [in Chinese]. Chin J Sch Health. 2013;34(2):136-8.

56. *Zhang R. Analysis of health risk behaviors of adolescents in Zhejiang Province [in Chinese]. Chin J Sch Health. 2013;33(4):20-3.

57. *Newman IM, Huang Z, Shell DF. Investigation and analysis of drinking patterns of college students [in Chinese]. Chin J Soc Med. 2014;31:105-8.

58. *Wan S. A correlative study on the subhealth state of college students and the use of tobacco and alcohol [in Chinese]. Chin Health Care Nutr. 2014;3: 1870-1.

59. *Zhang Y, Luo W, Chen W, Yao X. Results of health risk behaviors of adolescents in Changzhou in 2013 [in Chinese]. Chin J Sch Health. 2014; 35(9):1314-7.

60. *Du W, Zhao X, Li B, Zhang H, Liu S, Mao H. Analysis of drinking status and influencing factors of college students in Qinghai Province [in Chinese]. Chin J Dis Cont Prev. 2015;19:1070-4.

61. *Wang C, Tong F, Li X, Xu S, Gao G, Zhang X. Analysis of drinking situation and influencing factors in college students [in Chinese]. Chin J Sch Health. 2015;36(5):699-707.

\section{Submit your next manuscript to BioMed Central and we will help you at every step:}

- We accept pre-submission inquiries

- Our selector tool helps you to find the most relevant journal

- We provide round the clock customer support

- Convenient online submission

- Thorough peer review

- Inclusion in PubMed and all major indexing services

- Maximum visibility for your research

Submit your manuscript at www.biomedcentral.com/submit
() Biomed Central 